\title{
Pumping Performance Analysis on Crushed Sand Concrete
}

\author{
Lei YU*, Lei CHEN, Zhaolei LIU \\ Beijing Xin-Qiao Technology Development Co., LTD, \\ Beijing, China \\ e-mail: 270263604@qq.com, 562008917@qq.com, 14082717@qq.com
}

\begin{abstract}
By means of laboratory experiment, pump performance of crush sand concretes with different stone powder content and methylene blue value are measured. More stone powder provides better lubrication and better pump performance on low-strength concrete. Paste viscosity increases by increasing stone powder in high- strength concrete and lead to poor pump performance. Based on Bayes Discriminant Analysis, discrimination diagrams for forecast pump performance are available for low-strength and highstrength concrete separately.
\end{abstract}

Keywords-concrete; crushed sand; pumping; bayes discriminant analysis; insert

\section{INTRODUCTION}

A Concrete flows could be compressed during pumping because of gravity and other external force such as vibration and friction. Mortar and aggregates are different in density and size. Angularity of crushed sand lead to larger friction than nature sand [1]. So, Segregation more often happens on crushed sand concrete when pumping. A lot of experiment data indicate that pumping resistance of crushed sand concrete can be affected by stone powder content and methylene blue (MB) value. $\mathrm{MB}$ value is the representative of mud content in crushed sand. Stone powder and MB value vary with batch or factory [2]. Finding a principle to distinguish concrete pump performance by these tow parameters is important.

\section{LABORATORY EXPERIMENT}

Tests were conducted on both low-strength concrete and high-strength concrete.

\section{EXPERIMENT DESIGN}

\section{A. Concrete Mix Proportion}

Select low-strength concrete C30 and high-strength concrete C60 concrete as the candidates. Table 1 shows the concrete mix proportion.

TABLE I. MIX PROPORTION OF CONCRETE [KG/M³]

\begin{tabular}{|c|c|c|c|c|}
\hline Concrete ID & Cement & $\begin{array}{c}\text { Crushe } \\
\text { d sand }\end{array}$ & Stone & Water \\
\hline C30 & 380 & 867 & 978 & 175 \\
\hline C60 & 500 & 774 & 1.26 & 175 \\
\hline
\end{tabular}

\section{B. Experiment step}

Put crushed sand on $0.075 \mathrm{~mm}$ sifter and sieve. Separate crushed sand into two parts. According to designing stone powder content and $\mathrm{MB}$ value in table 2, mix above sifter crush sand and below sifter stone powder. Fineness modulus all adjust to 2.8. MB value can be controlled by adding clay powder. By adding water reducer, adjust slumps among 160180 and divergences among 450-500 $\mathrm{mm}$. Put mixture into pump resistance device and start pumping simulation. Record pump distance and pump resistance force value.

TABLE II. Stone Power Content And MB VAlue

\begin{tabular}{cccc}
\hline Concrete & ID & Stone Powder content [\%] & MB Value \\
C30 & 1 & 5 & 0.25 \\
& 2 & 10 & 0.25 \\
& 3 & 15 & 0.25 \\
& 4 & 20 & 0.25 \\
& 5 & 10 & 0.70 \\
& 6 & 10 & 1.40 \\
& 7 & 10 & 2.10 \\
& 8 & 5 & 0.25 \\
& 9 & 7 & 0.25 \\
& 10 & 10 & 0.25 \\
& 11 & 7 & 0.70 \\
& 12 & 7 & 1.40 \\
\hline
\end{tabular}

C. Stone Powder content and MB value design

Measure their stone powder contents and MB value. Table 2 shows stone powder contents and MB value.

\section{EXPERIMENT RESULT ANALYSIS}

\section{A. Pump Performance Analysis}

Table 3 is collection of experiment data.

TABLE III. Pump Performance ON LOW-Strength CONCRETE

\begin{tabular}{|c|c|c|c|c|}
\hline ID & $\begin{array}{c}\text { Stone } \\
\text { powder } \\
\text { content } \\
{[\%]}\end{array}$ & $\begin{array}{l}\text { MB } \\
\text { value }\end{array}$ & $\begin{array}{c}\text { Pump } \\
\text { distance }[\mathrm{mm}]\end{array}$ & $\begin{array}{l}\text { Average pump } \\
\text { resistance [MPa] }\end{array}$ \\
\hline 1 & 5 & 0.25 & 410 & $\infty$ \\
\hline 2 & 10 & 0.25 & 740 & $\infty$ \\
\hline 3 & 15 & 0.25 & 1000 & 1.202 \\
\hline 4 & 20 & 0.25 & 1000 & 1.156 \\
\hline 5 & 10 & 0.7 & 820 & $\infty$ \\
\hline 6 & 10 & 1.4 & 1000 & 1.100 \\
\hline 7 & 10 & 2.1 & 1000 & 1.078 \\
\hline
\end{tabular}


For low-strength concrete, below $10 \%$ stone powder content is hard to pumping. Pump resistance decreases by stone powder content increasing. This is because more stone powder provides better lubrication. Crushed sand angularity is weaken. At the same time, larger MB value leads to better pump performance by increasing cohesion.

For high-strength concrete, higher stone powder content and $\mathrm{MB}$ value is harmful to pump performance. This is because high-strength concrete have more cement and lower water cement ratio. Paste viscosity increases by increasing powder.

TABle IV. Pump Performance on High-Strength Concrete

\begin{tabular}{ccccc}
\hline ID & $\begin{array}{c}\text { Stone } \\
\text { powder } \\
\text { content } \\
{[\%]}\end{array}$ & $\begin{array}{c}\text { MB } \\
\text { value }\end{array}$ & $\begin{array}{c}\text { Pump } \\
\text { distance } \\
{[\mathrm{mm}]}\end{array}$ & $\begin{array}{c}\text { Average pump } \\
\text { resistance [MPa] }\end{array}$ \\
\hline 1 & 5 & 0.25 & 1000 & 1.516 \\
2 & 7 & 0.25 & 1000 & 1.538 \\
3 & 10 & 0.25 & 408 & $\infty$ \\
4 & 7 & 0.7 & 660 & $\infty$ \\
5 & 7 & 1.4 & 470 & $\infty$ \\
6 & 7 & 2.1 & 381 & Note: $\infty$-pump unsuccessful.
\end{tabular}

\section{BAYES DisCRIMINANT ANALYSIS ON CONCRETE PUMP PERFORMANCE}

Bayes discriminant is adopted that you have some acknowledge on study body. Acknowledge can be described by prior probability. Prior probability distribution can be corrected by sample and then posterior probability distribution is available. At last, any forecast can be done according to posterior probability distribution [3].

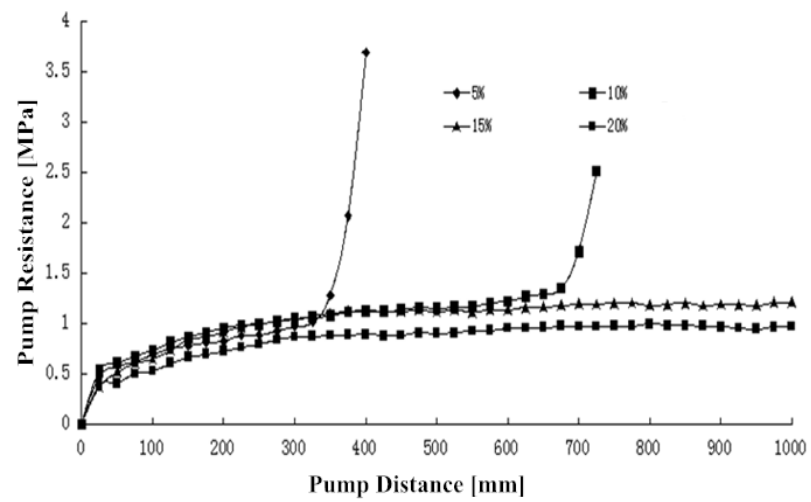

Figure 1. Pump distance VS pump resistance on low-strength concrete.

\section{A. Parameters design}

Stone powder content and MB value are two forecast factors. For low-strength concrete, according to experiment data, 3 ID is defeated when pumping and 4 ID come through. Prior probabilities are 3/7 and 4/7 separately. Assume misjudgment rate equal. For high-strength concrete, according to experiment data, 4 ID is defeated when pumping and 2 ID come through. Prior probabilities are $2 / 3$ and $1 / 3$ separately. Assume misjudgment rate equal. Use $\mathrm{R}$ software to do Bayes Discriminant Analysis [4].

\section{BAYES DISCRIMINANT ANALYSIS RESULTS}

Fig.2 is discrimination diagram of crushed sand concrete pumping performance.
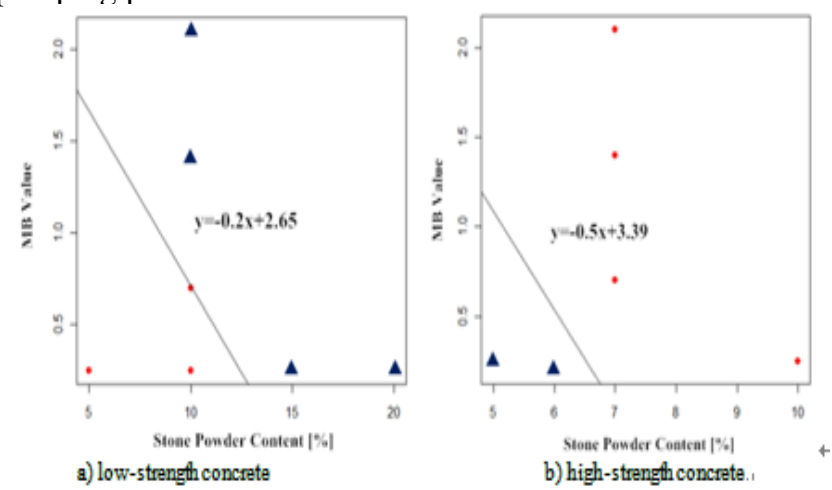

Figure 2. Discrimination diagram.

Round points pump successfully. Triangle points pump unsuccessfully. Distinguish line separates diagram into two parts. For low-strength concrete, Line below is couples of stone powder content and MB value for pump unsuccessfully and above line is opposite. For high-strength concrete, Line below is pump successfully and above is opposite.

\section{SUMMARY}

By means of laboratory experiment, pump performance of crush sand concretes with different stone powder content and $\mathrm{MB}$ value are measured. Conclusions are as follow:

For low-strength concrete, pump resistance decrease by stone powder content increasing because more stone powder provides better lubrication.

For high-strength concrete, higher stone powder content and MB value is harmful to pump performance. Paste viscosity increases by increasing powder.

Based on Bayes Discriminant Analysis, discrimination diagrams for forecast pump performance are available.

(1) Figures; table heads should appear above the tables. Insert figures and tables after they are cited in the text. Use the abbreviation "Fig. 1", even at the beginning of a sentence.

\section{ACKNOWLEDGEMENT}

This research was financially supported by the Innovating Foundation of Beijing Xin-Qiao Technology Development Co., LTD.

\section{REFERENCES}

[1] Myoung Sung Choi, Seung Hee Kwon, Prediction on pipe flow of pumped concrete based on shear-induced particle migration,Cement and Concrete Research,2013,52, pp.216-224.

[2] Jian XU, Ji-Wei CAI, Ji-Liang WANG, Research status of crush sand and concrete [J]. Building Materials Abroad, 2004, 25(3), pp: 20-24.

[3] Shou-Kui SI, Zhao-Liang SUN, Mathematical modeling, National Defense Industry Press, 2015.

[4] Yi XUE, Li-Ping CHEN, Statistical 1 modeling and R software, Tsinghua University Industry Press, 2007. 